\title{
Evolving Equity Market Interdependencies: Evidence from Emerging Markets
}

\author{
Shalini Talwar ${ }^{1}$ \\ ${ }^{1}$ K J Somaiya Institute of Management Studies \& Research, Mumbai, India \\ Correspondence: Shalini Talwar, K J Somaiya Institute of Management Studies \& Research, Vidyanagar, \\ Vidyavihar (East) Mumbai, 400 077, India. Tel: 91-989-285-7650. E-mail: shalini.t@ somaiya.edu
}

Received: May 8, 2015

doi:10.5539/ijef.v7n8p38
Accepted: May 22, 2015

Online Published: July 25, 2015

\begin{abstract}
This paper examines dynamic linkages among the equity markets of Mexico, Indonesia, Nigeria and Turkey employing dollar denominated daily closing price data of the chosen indices from January 2000 through December 2014. Empirical tests have been conducted for three periods: January 1, 2000-December 5, 2014; January 1, 2000-December 31, 2008 and January 1, 2009-December 5, 2014 to ascertain the causality and transmission of shock among these markets. The results of summary statistics of VAR reveal that some indices have causality relationships, indicating primacy of information content and efficacy in making superior predictions. Most markets Table large extent of contemporaneous correlation with their own innovation and the impact of other markets on their variance is limited to under $15 \%$. Further, the interdependencies seem to be shifting, albeit subtly, in the post crisis period.
\end{abstract}

Keywords: time-series models, financial econometrics, financial crises, portfolio choice, international financial markets

\section{Introduction}

Investors and portfolio managers across the world are keen to identify new opportunities for international portfolio diversification in an effort to enhance their expected returns at lower volatility. The advantages of cross-border investment have been underscored in many studies over the years. For instance, Lessard (1973), Levy and Sarnat (1970) and Solnik (1974) have highlighted the benefits of investing across national borders in their respective papers. However, just investing across the border would not guaranteed higher returns. For sustained positive outcome of portfolio diversification decision, investors need to be extremely careful in the choice of assets to be included in their portfolio.Choice of assets, in turn, is influenced to a great extent by the inter-relationship among the asset classes as well as assets within a class. Portfolio theories proposed by the Markowitz (1952), Sharpe (1964) and Lintner (1965) are also based on the concept of interdependence of various assets in a portfolio. Therefore, an understanding of the inter-relationship among various assets is essential for making more informed portfolio investment decisions.

The interest of international investors seems to be shifting gradually from financial assets issued by advanced economies to those issued by emerging economies, as the capital markets of the latter tend to offer better opportunities for higher returns. Within emerging markets, the interest of the investors remained focused on the BRICS countries for quite sometime but now the portfolio managers seem to be scouting for newer markets with untapped valuation potential. This is where MINT countries, the group being studied in the current paper, come in as they present an investment opportunity for holding a portfolio diversified across markets in four continents.

The term MINT is an acronym coined by Terence James O'Neill who is also the originator of BRICS grouping. MINT stands for Mexico, Indonesia, Nigeria and Turkey respectively. These countries represent newly emerging economies. O'Neill has justified clubbing them together on the basis of their future economic potential and their current macroeconomic situation. Given the fact that BRICS grouping has culminated into proposal of a BRICS bank; analysts, researchers and policy makers would not want to overlook MINT, another grouping that could probably turn out to be as promising a development in global economics.

The author proposes to examine MINT as a group with the main objective of studying the inter-linkages among the equity markets of these countries. Such a study is significant because, as mentioned above, these countries 
may together represent potentially lucrative investment opportunities for fund managers and investors seeking newer avenues for diversifying their investment holdings. A decision to invest in the assets in these countries as a group would depend on the inter-relationship among them.Such inter-linkages among assets and markets can be guaged through correlation, causality and the impact of transmission of shock or innovation. Correlation (or covariance) measures the degree of co-movement between assets and it has the potential to affect the portfolio balancing strategies of investors. Causality indicates information precedence and usefulness in predicting the futures values of a given asset better. Clarity about direction of causality among the MINT markets can serve as a basis for making more accurate forecasts of their value. Further, the study of linkages is also crucial for assessing contagion risk or domino effect i.e. the risk of diffusion of shock from one market to another. If any market in the MINT group is impacted to a large extent by innovation or news in the other three, then its inclusion in portfolio along with other three markets might not yield the benefit of diversification. The current study investigates correlation, causality as well as transmission of shock among the MINT countries using the Granger causality test and the vector autoregressive (VAR) framework. The author has examined the dynamic inter-linkages among the equity markets of MINT countries by applying the relevant tests to the price data of key equity indices for three periods: January 1, 2000-December 5, 2014 (P1); January 1, 2000-December 31, 2008 (P2), and January 1, 2009-December 5, 2014 (P3). The study compares the inter-linkages among MINT markets in the pre-financial crisis (2008) and post-financial crisis period to formulate a better understanding of their evolving dynamics. The study is confined to equity markets, as it is a commonly known fact that equity shares form a large part of the international portfolio diversification efforts.

The current study contributes to new knowledge because as far as the author is aware, there is no study that focuses on the evolving dynamic linkages among equity markets of Mexico, Indonesia, Nigeria and Turkey. Review of existing literature has revealed very few studies that have investigated interdependencies among the equity markets from the perspective of different time periods.

This paper has found the existence of some causality relationships that can be used for forecasting the future values of certain indices with more accuracy. The summary statistics of VAR confirm the existence of lucrative portfolio diversification opportunities for international investors in the short run. The results of the study for the pre and post crisis period have given mixed results, but the signs of changing dynamics among MINT markets in the recent past are quite evident.

The author expects the results of the study to be useful for fund managers and investors who are keen to induct equity of newer emerging markets in their investment portfolios and insightful for researchers pursuing research in this area.

\section{Literature Review}

In the current times, investors remain indifferent to nationality of any asset and seem to be more concerned about the expected returns and volatility. The importance of return has been highlighted in many studies including the portfolio balance model (Branson \& Henderson, 1985), which argues that, other things being equal, investors tend to hold an asset offering higher return in greater proportion as compared with a competing asset offering lower return. The returns of any asset or market are affected by a number of factors including their inter-relationship with other assets or markets.

Since the stock market crash of October 1987, interdependence among national equity markets, as represented by their key indices, has been extensively tested and documented in the empirical literature related to financial markets.

The inter-linkages among assets or markets, as measured by causation and correlation, are important inputs for portfolio investment decisions. Low international correlation across markets serves as the main basis of portfolio diversification and study of interdependence, as illustrated in the results of studies by Grubel and Fadner (1971), Erb et al. (1994) and Engle (2002).

Causation and interdependence amongst national markets has also been examined extensively by use of Granger Causality test, Johansen's cointegration test and the VAR framework. The VAR framework has been discussed in detail by many authors like Culbertson (1996), Mills (1999) and Tsay (2001). Studies by Dungey, Fry and Martin, (2003), Wong et al. (2004) and Cheng \& Glascock (2006) have also extensively discussed inter-linkages among equity markets around the world. Agiakloglou, C., and Gkouvakis, M. (2015) used causality and impulse responses to examine the bilateral relationships among market fundamental variables, such as stock returns and index returns for European Telecommunications institutions.

Most of the studies related to linkages among national markets have focused on advanced economies as seen in 
Yang and Doong (2004) and Francis et al. (2006). However, in the recent past, some studies like those by Tai (2007), Morales (2008), Yang and Chang (2008) have discussed such linkages with regard to emerging markets. The spillover effect of US financial market over the financial markets of emerging economies has been studied by Kayani and Gulzar (2013) using VectorAutoregressive (VAR) model. Impulse response functions computed in the study demonstrated that shock in US market impacted the returns of stocks of emerging markets. Meric et.al (2012) found that contemporaneous co-movements of Asian stock markets had moved closer during the period January 1, 2001-January 1, 2011, reducing the portfolio diversification benefits offered by them. Quraishi, A. H., \& Nanjegowda, H. (2014) investigated the impact of foreign institutional investors (FIIs) investment on S \& P Nifty Index using Granger Causality Test and Co integration analyses to test the long run relationship between the these variables. Research focused on emerging markets is definitely gaining momentum.

\section{Data Used for Analysis}

\subsection{Data Description}

The dollar-denominated daily closing prices of MINT stock market indices namely Mexican Stock Exchange Mexican Bolsa IPC Index (MEXBO), Jakarta Stock Exchange Composite Index (JCI), Nigerian Stock Exchange All Share Index (NGSEI) and Borsa Istanbul 100 Index (XU100) have taken from Bloomberg for a period from January 1, 2000 through December 5, 2014 for the purpose of the study and analysis. Dollar-denominated values are used so that indices representing different currencies are expressed in common monetary unit.

\subsection{Descriptive Statistics}

Firstly, to investigate the nature of the four indices, their descriptive statistics has been generated. Skewness, kurtosis, Jarque-Bera statistic and other measures have been calculated for all stock market indices. Such statistics are useful in providing elementary evidence about the behavior of time series and their respective distributions.

Table 1. Descriptive statistics of stock market indices

\begin{tabular}{lcccc}
\hline & DJCI & DMEXBO & DNGSE & DXU100 \\
\hline Mean & 0.000378 & 0.000381 & 0.000326 & $3.79 \mathrm{E}-05$ \\
Median & 0.001416 & 0.001234 & 0.000248 & 0.000957 \\
Maximum & 0.128918 & 0.151214 & 0.119186 & 0.200216 \\
Minimum & -0.16398 & -0.11532 & -0.11095 & -0.26341 \\
Std. Dev. & 0.01757 & 0.016574 & 0.014742 & 0.028215 \\
Skewness & -0.65312 & -0.05332 & -0.31771 & -0.33267 \\
Kurtosis & 11.07823 & 9.469861 & 12.5423 & 10.47722 \\
Jarque-Bera & 10616.6 & 6638.214 & 14500.09 & 8934.058 \\
Probability & 0 & 0 & 0 & 0 \\
\hline
\end{tabular}

Mean, median and mode give a general idea about the statistical nature of the time series under study. Skewness, Kurtosis and Jarque-Bera statistic give an idea about the distribution of the series. As can be seen in Table 1, all four indices have negative skewness. Negatively skewed distributions have a long left tail indicating a greater chance of extremely negative outcomes for investors. Absolute value of skewness for the Indonesian, Turkish and Nigerian indices above 0.2 indicates great skewness (Hildebrand, 1986), implying more outliers and chances of higher volatility of returns.

Since all indices are skewed, they follow leptokurtic distribution, as skewed distributions are always leptokurtic (Hopkins \& Weeks, 1990). Kurtosis values also reveal that all stock market indices follow Leptokurtic distribution, where large fluctuations are more likely to occur within the fat tails. The Nigerian market Tables the highest kurtosis at 12.54 , indicating a higher probability of occurrence of extreme values in this market. The Mexican stock market has the lowest value of kurtosis in the group at 9.47.

The Jarque-Bera statistic is used to test the null hypothesis that data is normally distributed. By using probability values of Jarque-Bera statistics, null hypothesis is rejected for all indices at $1 \%$ significance level. The indices are not normally distributed and this shows inefficiency in all the markets under study. 


\section{Methodology}

The author has applied a set of tests described below to achieve the objectives of the study.

\subsection{Unit Root Tests}

Almost all economic and financial time series Table trending behavior also called non-stationarity in the mean. A non-stationary data is trending data and cannot be of much use to draw inferences. Thus, non-stationarity needs to be detected and trends need to be removed before the series can be subjected to further analysis. In econometrics, non-stationarity is detected through tests designed to examine the presence of unit root. Once a non-stationary series is de-trended, it becomes stationary. i.e. mean reverting with broadly constant amplitude of fluctuations around this mean.

Since the index values being used in the current study represent financial time series, they may suffer from the problem of the existence of unit root at levels. Thus before commencing the analysis, data needs to be tested for stationarity. Augmented Dickey Duller (ADF) (1979, 1981) and Phillip Perron (PP) (1988) tests are the two commonly used tests for testing time series for non-stationarity. Researchers also tend to use KPSS test (1992) for more robust confirmation of stationarity.

The ADF test is based on the logic that a non- stationary process has infinite memory, as it does not show any decay in shock that takes place in the process. It tends to behave like AR (1) process with $\rho=1$. ADF test is designed to examine if $\rho=1$.

Mathematically:

$$
\begin{gathered}
y_{t}=\rho y_{t-1}+\varepsilon_{t} \\
\Rightarrow>y_{t}-y_{t-1}=\rho y_{t-1}-y_{t-1}+\varepsilon_{t} \\
\Rightarrow>\Delta y_{t}=(1-\rho) y_{t-1}+\varepsilon_{t} \\
\Rightarrow \Delta y_{t}=\delta y_{t-1}+\varepsilon_{t}
\end{gathered}
$$

For equation (1), the hypothesis tested is if $\delta=0$. The modified critical values tabulated in MacKinnon (1991) are used for this test. The lagged terms of $\Delta y_{t}$ are also included in the regression to get the white noise.

Lag length can alter the results of these tests, so lag length criteria should be investigated. Usually three methods: Akaike (1974), Schwarz (1978) and Hannan-Quinn (1979) are used for determination of lag length, as these are the classical procedures for determining lag length (Lutkepohl, 1993). In the current study, Schwarz Information Criteria (SIC) given by Schwarz is used for the unit root test.

Philip-Perron test is a non-parametric method for controlling higher order serial correlation in a time series. The test is free from parametric error and is represented as:

$$
y_{t}=c+d t+a y_{t-i}+e(t)
$$

In case of both ADF and PP tests, $\mathrm{H} 0$ is series has a unit root and $\mathrm{H} 1$ is series is stationary.

In KPSS test, Lagrange multiplier (LM) statistic is used to test the hypothesis of zero variance of random walk. In KPSS test: $\mathrm{H} 0$ is series is stationary; $\mathrm{H} 1$ is series has a unit root.

The test is symbolically expressed as:

$$
K P S S=\left(T^{-2} \sum_{t=1}^{T} \hat{S}_{t}^{2}\right) / \hat{\lambda}^{2}
$$

Where,

$\hat{s}_{t}^{2}$ represents the value of residual of a regression of $y_{t}$ on $D_{t}$.

$\hat{\lambda}^{2}$ represents an estimate of the long-run variance of residuals.

KPSS complements ADF and PP tests. By testing both the unit root as well as the stationarity hypothesis, it is possible to distinguish a series that appears to be stationary as against a series that appears to have a unit root and series for which the data is such that ADF and PP tests are not sufficiently informative to be indicate with certainty whether it is stationary or not.

In the current study, the closing levels have been tested for stationarity using ADF, PP and KPSS tests. The decision rule for the first two tests is to reject null hypothesis if t-statistic is less than the critical value. In practice, the two tests are interpreted on the basis of p-value (probability) of the test statistic. To interpret KPSS, 
the test statistic is compared with the critical value at desired significance level (usually 5\%). If the test statistic is higher than the critical value, the null hypothesis is rejected.

\subsection{Calculation of Logarithmic Growth Rate}

A time series that is stationary at level is called integrated of order 0 or I ( 0$)$ process. However, most financial time series have been observed to follow I (1) process i.e. they are non-stationary at level but become stationary after taking the first difference, For this purpose, generally the difference of the natural log of the series is taken, which is called logarithmic growth rate. The index values are log-transformed using the following formula:

$$
r=\ln \left(P_{t} / P_{t-1}\right) * 100
$$

Where, $\mathrm{r}=$ return, $\mathrm{P}_{\mathrm{t}}=$ Price of the day, $\mathrm{P}_{\mathrm{t}-1}=$ Price of the previous day

\subsection{Granger Causality Test}

Granger causality test is a statistical approach proposed by Granger $(1969,1988)$ to infer cause and effect relationship between time series under study. The test is based on logic that effect cannot precede cause. When a variable is said to Granger cause the other, it implies that the variable Granger causing the other helps to make a more accurate prediction of the other variable than a prediction made solely on the basis of the historical values of the variable that is Granger caused. Thus, given two financial time series $x_{t}$ and $y_{t}, x_{t}$ is said to Granger cause $\mathrm{y}_{\mathrm{t}}$ if future movement of $\mathrm{y}_{\mathrm{t}}$ can be better predicted using the past values of both $\mathrm{x}_{\mathrm{t}}$ and $\mathrm{y}_{\mathrm{t}}$, than it can be by using the past values of $y_{t}$ alone.

Following regression equations represent traditional Granger Causality

$$
\begin{gathered}
y_{t}=\varphi+\sum_{i=1}^{l} \alpha_{i} y_{t-i}+\sum_{j=1}^{l} \beta_{j} x_{t-j}+\varepsilon_{t} \\
x_{t}=\omega+\sum_{i=1}^{l} \gamma_{i} x_{t-i}+\sum_{j=1}^{l} \theta_{j} y_{t-j}+\varepsilon_{t}
\end{gathered}
$$

Unidirectional relationship from $\mathrm{x}$ to $\mathrm{y}$ is indicated if the estimated coefficients on the lagged value of $\mathrm{x}$ are statistically different from zero as a group in (5) and the set of estimated coefficients on the lagged value of $y$ in (6) are not statistically different from zero. Unidirectional causality from $\mathrm{y}$ to $\mathrm{x}$ if the lagged values $\mathrm{x}$ coefficients in (5) are not statistically different from zero and the set of the estimated coefficients on the lagged y in (6) are statistically different from zero. If the sets of $\mathrm{x}$ and $\mathrm{y}$ coefficients are statistically significantly different from zero in regression (5) as well as (6), bilateral causality exists.

\subsection{Vector Autoregression Model (VAR)}

VAR is considered to be an effective test for studying the dynamic influence of shocks on a system of variables. Its main advantage is that it does not need structural modelling as it models each endogenous variable as a function of the lagged values of all endogenous variables in the system, including itself.

In standard VAR, all the variables are treated as endogenous variables and the regressors include only lagged values of these endogenous variables. In compact terms, VAR model for $k$ variables can be written in matrix notation as follows:

$$
y_{t}=a_{0}+A_{1} y_{t-1} \ldots+A_{p} y_{t-p}+\varepsilon_{t}
$$

Where $y_{\mathrm{t}}$ is a vector of all the $\mathrm{k}$ variables included in the system, $a_{0}$ is $\mathrm{k} \times 1$ vector of intercepts, $\mathrm{A}_{1}, \mathrm{~A}_{2}, \ldots, \mathrm{A}_{\mathrm{p}}$ are $(\mathrm{k} * \mathrm{k})$ matrix coefficients and $\varepsilon_{\mathrm{t}}$ is the $k$-dimensional vector of error terms and $p$ is the optimal number of lag length. The vector of error term is assumed to follow a multivariate normal distribution and have zero autocorrelation. Symbolically,

$$
\varepsilon_{t} \sim \operatorname{iidN}_{\mathrm{k}}(0, \Sigma)
$$

where $\sum$ is the variance covariance matrix of the error vector that can be expanded as follows:

$$
\Sigma=\left[\begin{array}{ll}
\sigma_{11}^{2} & \sigma_{12} \\
\sigma_{21} & \sigma_{22}^{2}
\end{array}\right]
$$

VAR lag length can be chosen using SIC and other criteria described above.

Due to the existence of contemporaneous correlations, there is an inbuilt multicollinearity in the VAR model which makes the direct interpretation of VAR coefficients rather difficult. Therefore, summary statistics of VAR, namely Block Exogeneity Wald Test and impulse response function or variance decomposition are used for interpretation of the output. 


\subsubsection{Block Exogenity Wald Test}

It evaluates causality by examining the joint significance of lagged coefficients of a variable in the equation of another variable. This kind of significance testing can be performed with the usual F-test or Wald-test used for evaluation of parameter restrictions. For two variables, the causality can be examined by testing the following hypothesis:

\section{Hypothesis: 1}

$\mathrm{y}$ does not cause $\mathrm{x}$ :

$$
H 0: \lambda_{12}^{1}+\lambda_{12}^{2}+\lambda_{12}^{3}=0
$$

y causes $\mathrm{x}$ :

$$
H 1: \lambda_{12}^{1}+\lambda_{12}^{2}+\lambda_{12}^{3} \neq 0
$$

\section{Hypothesis: 2}

$\mathrm{x}$ does not cause $\mathrm{y}$ :

$$
H 0: \lambda_{21}^{1}+\lambda_{21}^{2}+\lambda_{21}^{3}=0
$$

$\mathrm{x}$ causes $\mathrm{y}$ :

\subsubsection{Impulse Response Function}

$$
H 1: \lambda_{21}^{1}+\lambda_{21}^{2}+\lambda_{21}^{3} \neq 0
$$

It enables the tracing of time path of the impact of a shock in one variable on all the variables included in the VAR model. The results depend on the order of the variables in the VAR system. A stable VAR model of order $\mathrm{k}$ is represented as an infinitive order vector moving average (VMA) process that can be mathematically expressed as:

$$
y_{t}=\mu+\varepsilon_{t}+\varphi_{1} \varepsilon_{t-1}+\varphi_{2} \varepsilon_{t-2} \ldots \propto
$$

The above equation serves as the main basis to study the impulse response function.

\subsubsection{Variance Decomposition}

It is an alternative way to present the impact of shock on a market. It measures how much percent of the variance of a variable (y) can be explained by one unit shock in another variable (x). Variance decomposition focuses on variance of the response variable, $y$. The variance in $y$ can be expressed as:

$$
\operatorname{Var}(y)=E(\operatorname{Var}[y \mid x])+\operatorname{Var}(E[y \mid x])
$$

The first part captures the expected variance of $\mathrm{y}$ in response to shocks in $\mathrm{x}$ and the second part captures the variance of the "expected variance of $\mathrm{y}$ " in response to shocks in $\mathrm{x}$.

Cholesky decomposition used in VAR summary tests is sensitive to the order of variables in VAR model. Since VAR simulates the responses of a market to innovations or shocks in the other markets, time zone ordering is a key consideration while working with equity markets. In the current study, the time zone ordering used is: Indonesia, Turkey, Nigeria and Mexico.

\section{Results of Empirical Tests and Discussion}

The results of the econometric tests and their interpretation are given below.

\subsection{Unit Root Tests}

All time series are found to follow I (1) process i.e. non-stationary at levels but stationary at first difference. For $\mathrm{ADF}$ and PP, the test statistic is found to be statistically insignificant at levels as the p-values are greater than 0.05 , as tabulated in Table 2. As a consequence, the null hypothesis that the series had unit root could not be rejected at levels. The t-statistic for the two tests is found to be statistically significant at first difference, confirming stationarity. For interpreting KPSS test results, the LM test statistic is compared with the asymptotic critical values at 5\% significance level to reject the null hypothesis of stationarity at levels but not at first difference. Hence, all four time series were found to be stationary at first difference by all three tests. 
Table 2. Results of unit root test

\begin{tabular}{ccccccccccc}
\hline & \multicolumn{4}{c}{ ADF TEST STAT } & \multicolumn{3}{c}{ PP TEST STAT } & \multicolumn{3}{c}{ K PSS LM TEST STAT*** } \\
\cline { 2 - 10 } & Level & Prob.* & I Diff. & Prob.* & Level & Prob.*** & I Diff. & Prob.** & Level & I Diff. \\
\hline MEXBO & -1.146 & 0.699 & -55.749 & 0.0001 & -1.082 & 0.725 & -55.495 & 0.0001 & 7.274 & 0.056 \\
JCI & -0.531 & 0.883 & -57.116 & 0.0001 & -0.469 & 0.895 & -57.000 & 0.0001 & 7.455 & 0.118 \\
NGSE & -1.493 & 0.537 & -32.716 & 0.0000 & -1.458 & 0.555 & -45.726 & 0.0001 & 1.902 & 0.284 \\
XU100 & -1.516 & 0.526 & -59.750 & 0.0001 & -1.586 & 0.489 & -59.767 & 0.0001 & 5.339 & 0.123 \\
\hline
\end{tabular}

Note. *MacKinnon (1996) one-sided p-values, Exogenous: Constant \& Lag Length: 1 (based on SIC, maxlag=29);

**MacKinnon (1996) one-sided p-values, Exogenous: Constant, Bandwidth: 13 (Newey-West automatic) using Bartlett kernel;

***Exogenous: Constant, Bandwidth: 19 (Newey-West automatic) using Bartlett kernel, Asymptotic critical values at 5\% significance level is 0.463, Kwiatkowski-Phillips-Schmidt-Shin (1992, Table 1).

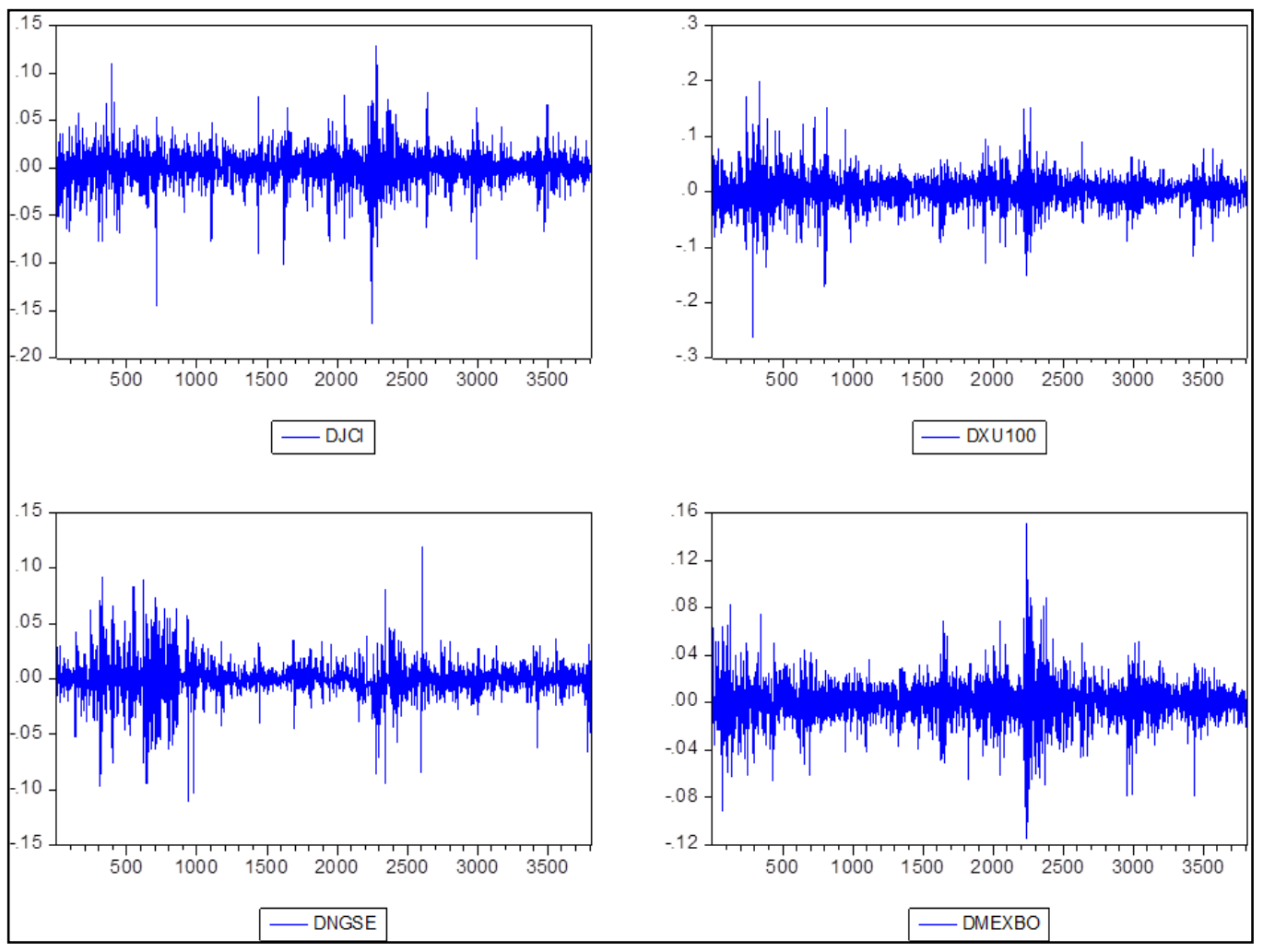

Figure 1. Time series plot of returns

Stationarity of the series can also be visually confirmed with the time series plot of lognormal returns of the four markets as illustrated in Figure 1. The returns can be observed to fluctuate around a constant mean, i.e. they are mean reverting. This confirms that they follow a stationary process.

\subsection{Correlation Matrix}

Table 3 illustrates the correlations between the pairs of markets under study for all periods. Using the returns data for P1, statistically significant positive correlation is found between MEXBO \& JCI, MEXBO \& XU100, and JCI \& XU100. However, it is low enough for these markets to offer some short-run advantages of diversification. Correlations between other pairs of markets are statistically insignificant at $5 \%$ significance level. 
Table 3. Correlation Matrix for P1, P2 \&P3

\begin{tabular}{|c|c|c|c|c|c|c|c|c|c|c|c|c|}
\hline & $\mathrm{J}$ & $\mathrm{X}$ & $\mathrm{N}$ & $\mathrm{M}$ & $\mathrm{J}$ & $\mathrm{X}$ & $\mathrm{N}$ & $\mathrm{M}$ & $\mathrm{J}$ & $\mathrm{X}$ & $\mathrm{N}$ & $\mathrm{M}$ \\
\hline \multirow{3}{*}{$\mathrm{J}$} & 1 & & & & 1 & & & & 1 & & & \\
\hline & ----- & & & & ----- & & & & ---- & & & \\
\hline & ---- & & & & ----- & & & & ---- & & & \\
\hline \multirow{3}{*}{$X$} & $0.234 *$ & 1 & & & 0.188 & 1 & & & 0.382 & 1 & & \\
\hline & $14.852 * *$ & ----- & & & 9.145 & ----- & & & 16.080 & ----- & & \\
\hline & $0 * * *$ & ----- & & & 0 & ----- & & & 0 & ----- & & \\
\hline \multirow{3}{*}{$\mathrm{N}$} & -0.026 & 0.013 & 1 & & -0.06 & -0.009 & 1 & & 0.06 & 0.087 & 1 & \\
\hline & -1.634 & 0.772 & ----- & & -2.886 & -0.476 & ----- & & 2.349 & 3.406 & ----- & \\
\hline & 0.102 & 0.44 & ---- & & 0.004 & 0.634 & ---- & & 0.019 & 0.0007 & ----- & \\
\hline \multirow{3}{*}{ M } & 0.244 & 0.379 & -0.002 & 1 & 0.198 & 0.315 & -0.018 & 1 & 0.347 & 0.552 & 0.036 & 1 \\
\hline & 15.549 & 24.782 & -0.101 & --- & 9.656 & 15.907 & -0.861 & ----- & 14.371 & 25.749 & 1.419 & ----- \\
\hline & 0 & 0 & 0.919 & --- & 0 & 0 & 0.3895 & ----- & 0 & 0 & 0.156 & ----- \\
\hline
\end{tabular}

The correlations are confirmed to be almost same with pre-crisis data. The only noticeable change is an increased, statistically significant, negative correlation between NGSE and JCI, indicating lucrative diversification opportunities. In the post-crisis period, the correlation between NGSE \& JCI and NGSE \& XU100 is found to be positive and statistically significant as well. Largely the correlations between pairs of MINT markets are found to be the same by analyzing data for all three periods. However, positive correlation between pairs of markets is higher in the post-crisis period, indicating a trend towards more interdependence among the markets under study.

\subsection{Granger Causality Test}

Granger Causality is inferred by checking the statistical significance of p-values of the test statistic at 5\% significance level where the low p-values are used to reject the null hypothesis of ' $x$ does not Granger Cause $y$ ', as tabulated in Table 4. Bidirectional causality exists between MEXBO \& JCI as per returns data for P2. The returns data for the other two periods indicates unidirectional causality from MEXBO to JCI. Unidirectional causality from JCI to NGSE and XU100 to JCI is confirmed by the analysis of returns data for all three periods. Further, the returns data for P1 and P3 indicate a unidirectional causality from MEXBO to NGSE.

Though no causality relationship is indicated between XU100 and NGSE by data pertaing to P1 and P2, but, unidirectional causality from XU100 to NGSE is confirmed by returns data for P3. The economic relations between the two countries need to be studied further to understand the underlying economic reasons, if any, for emergence of such causality in the recent past. Analysis of data for P1 and P2 also indicates bidirectional causality between MEXBO \& XU100. However, only unidirectional causality from MEXBO to XU100 was confirmed by data for post-crisis period. Again the changing dynamics needs to be understood in the macroeconomic context.

Table 4. Pair-wise granger causality test for P1, P2 \& P3

\begin{tabular}{|c|c|c|c|c|c|c|c|c|c|c|c|}
\hline $\mathrm{H} 0$ & F-Stat. & Prob. & Interpretation & $\mathrm{HO}$ & F-Stat. & Prob. & Interpretation & $\mathrm{H} 0$ & F-Stat. & Prob. & Interpretation \\
\hline MEXBO & 133.5 & $9.0 \mathrm{e}-57$ & MEXBO & MEXBO & 73.34 & $1.0 \mathrm{e}-31$ & MEXBO & MEXBO & 71.17 & $3.0 \mathrm{e}-3$ & MEXBO \\
\hline doesn't & & & Granger Causes & doesn't & & & Granger & doesn't GC & & & Granger \\
\hline GC JCI & & & JCI & GC JCI & & & Causes JCI & JCI & & & Causes JCI \\
\hline JCI doesn’t & 1.39 & 0.2469 & & JCI doesn’t & 3.67 & 0.0256 & JCI Granger & JCI doesn’t & 2.18 & 0.113 & \\
\hline GC MEXBO & & & & GC MEXBO & & & Causes & GC MEXBO & & & \\
\hline & & & & & & & MEXBO & & & & \\
\hline NGSE & 1.11 & 0.3302 & & NGSE & 0.41 & 0.6613 & & NGSE & 1.04 & 0.353 & \\
\hline doesn't & & & & doesn't & & & & doesn't GC & & & \\
\hline GC JCI & & & & GC JCI & & & & JCI & & & \\
\hline JCI doesn't & 11.26 & $1.0 \mathrm{e}-05$ & JCI Granger & JCI doesn't & 4.85 & 0.0079 & JCI Granger & JCI doesn't & 6.45 & 0.001 & JCI Granger \\
\hline GC NGSE & & & Causes NGSE & GC NGSE & & & Causes NGSE & GC NGSE & & & Causes NGSE \\
\hline
\end{tabular}




\begin{tabular}{|c|c|c|c|c|c|c|c|c|c|c|c|}
\hline $\begin{array}{l}\text { XU100 } \\
\text { doesn't } \\
\text { GC JCI }\end{array}$ & 17.40 & $3.0 \mathrm{e}-08$ & $\begin{array}{l}\text { XU100 Granger } \\
\text { Causes JCI }\end{array}$ & $\begin{array}{l}\text { XU100 } \\
\text { doesn't } \\
\text { GC JCI }\end{array}$ & 7.12 & 0.0008 & $\begin{array}{c}\text { XU100 } \\
\text { Granger } \\
\text { Causes JCI }\end{array}$ & $\begin{array}{l}\text { XU100 } \\
\text { doesn't } \\
\text { GC JCI }\end{array}$ & 28.59 & 7.0e-1 & $\begin{array}{c}\text { XU100 } \\
\text { Granger } \\
\text { Causes JCI }\end{array}$ \\
\hline JCI doesn't & 0.81 & 0.4247 & & JCI doesn't & 0.13 & 0.8744 & & JCI doesn't & 2.75 & 0.064 & \\
\hline GC XU100 & & & & GC XU100 & & & & GC XU100 & & & \\
\hline $\begin{array}{l}\text { NGSE } \\
\text { doesn’t }\end{array}$ & 0.62 & 0.5395 & & $\begin{array}{l}\text { NGSE } \\
\text { doesn't }\end{array}$ & 0.20 & 0.8165 & & $\begin{array}{l}\text { NGSE } \\
\text { doesn't }\end{array}$ & 3.49 & 0.030 & \\
\hline GC MEXBO & & & & GC MEXBO & & & & GC MEXBO & & & \\
\hline $\begin{array}{l}\text { MEXB } \\
\text { doesn't }\end{array}$ & 6.39 & 0.0017 & $\begin{array}{c}\text { MEXBO } \\
\text { Granger Causes }\end{array}$ & $\begin{array}{c}\text { MEXBO } \\
\text { doesn't }\end{array}$ & 0.37 & 0.692 & & $\begin{array}{c}\text { MEXBO } \\
\text { doesn't }\end{array}$ & 15.53 & $2.0 \mathrm{e}-0$ & $\begin{array}{l}\text { MEXBO } \\
\text { Granger }\end{array}$ \\
\hline GC NGSE & & & NGSE & GC NGSE & & & & GC NGSE & & & Causes NGSE \\
\hline $\begin{array}{l}\text { XU100 } \\
\text { doesn't }\end{array}$ & 2.66 & 0.0704 & & $\begin{array}{l}\text { XU100 } \\
\text { doesn't }\end{array}$ & 1.89 & 0.1514 & & $\begin{array}{l}\text { XU100 } \\
\text { doesn't }\end{array}$ & 7.35 & 0.0007 & $\begin{array}{l}\text { XU100 } \\
\text { Granger }\end{array}$ \\
\hline GC NGSE & & & & GC NGSE & & & & GC NGSE & & & Causes NGSE \\
\hline $\begin{array}{l}\text { NGSE } \\
\text { doesn't }\end{array}$ & 0.46 & 0.6302 & & $\begin{array}{l}\text { NGSE } \\
\text { doesn't }\end{array}$ & 1.42 & 0.2409 & & $\begin{array}{l}\text { NGSE } \\
\text { doesn't }\end{array}$ & 2.34 & 0.0966 & \\
\hline GC XU100 & & & & GC XU100 & & & & GC XU100 & & & \\
\hline $\begin{array}{l}\text { XU100 } \\
\text { doesn't }\end{array}$ & 4.36 & 0.0128 & $\begin{array}{l}\text { XU100 Granger } \\
\text { Causes MEXBO }\end{array}$ & $\begin{array}{l}\text { XU100 } \\
\text { doesn't }\end{array}$ & 4.31 & 0.0135 & $\begin{array}{l}\text { XU100 } \\
\text { Granger }\end{array}$ & $\begin{array}{l}\text { XU100 } \\
\text { doesn't }\end{array}$ & 0.17 & 0.845 & \\
\hline GC MEXBO & & & & GC MEXBO & & & $\begin{array}{c}\text { Causes } \\
\text { MEXBO }\end{array}$ & GC MEXBO & & & \\
\hline $\begin{array}{c}\text { MEXBO } \\
\text { doesn't }\end{array}$ & 48.74 & $1.0 \mathrm{e}-21$ & $\begin{array}{c}\text { MEXBO } \\
\text { Granger Causes }\end{array}$ & $\begin{array}{c}\text { MEXBO } \\
\text { doesn't }\end{array}$ & 39.99 & $8.0 \mathrm{e}-18$ & $\begin{array}{l}\text { MEXBO } \\
\text { Granger }\end{array}$ & $\begin{array}{c}\text { MEXBO } \\
\text { doesn't }\end{array}$ & 7.46 & 0.0006 & $\begin{array}{l}\text { MEXBO } \\
\text { Granger }\end{array}$ \\
\hline GC XU100 & & & XU100 & GC XU100 & & & Causes XU100 & GC XU100 & & & Causes XU100 \\
\hline
\end{tabular}

Note. GC stands for 'Granger Cause'; The highlighted boxes indicate statistically significant outcomes at 5\% significance level.

\subsection{Vector Autoregression}

Pair-wise Granger casuality test is conducted to identify influential markets among the four MINT markets. Since the test did not indicate any influential market in terms of precedence and information content, VAR is applied to study the impact and transmission of shock from one market to another. As mentioned above, time zone ordering used for VAR is: Indonesia, Turkey, Nigeria and Mexico.

\subsubsection{Lag Length Criteria}

Lag length of 1 is used for VAR estimation for P1 on the basis of SIC and HQ criteria, as tabulated in Table 5.The author has gone with the SIC criterion as it is severest in penalizing loss of degree of freedom.

Similarly, the lag length criteria were checked for P2 and P3. In the case of P2, SIC and HQ indicated lag length 1 whereas AIC and FPE indicated lag length 5. Lag length 1 was chosen on the basis of SIC criterion.

For P3, FPE, AIC, SC and HQ indicated the lag length 1, so the same was used.

Table 5. Lag length criteria

\begin{tabular}{lcccccc}
\hline Lag & LogL & LR & FPE & AIC & SC & HQ \\
\hline $\mathbf{0}$ & 39392.06 & NA & $1.15 \mathrm{e}-14$ & -20.75 & -20.74 & -20.74 \\
$\mathbf{1}$ & 39595.28 & 405.91 & $1.04 \mathrm{e}-14$ & -20.85 & $-20.81^{*}$ & $-20.83^{*}$ \\
$\mathbf{2}$ & 39617.10 & 43.53 & $1.04 \mathrm{e}-14$ & -20.85 & -20.79 & -20.83 \\
$\mathbf{3}$ & 39649.95 & 65.46 & $1.03 \mathrm{e}-14$ & -20.86 & -20.77 & -20.83 \\
$\mathbf{4}$ & 39673.87 & 47.62 & $1.02 \mathrm{e}-14$ & -20.86 & -20.75 & -20.82 \\
$\mathbf{5}$ & 39693.47 & 38.98 & $1.02 \mathrm{e}-14$ & -20.86 & -20.73 & -20.81 \\
$\mathbf{6}$ & 39706.82 & 26.52 & $1.02 \mathrm{e}-14$ & -20.86 & -20.69 & -20.80 \\
$\mathbf{7}$ & 39727.66 & 41.36 & $1.02 \mathrm{e}-14$ & -20.86 & -20.67 & -20.79 \\
$\mathbf{8}$ & 39745.41 & $35.19^{*}$ & $1.02 \mathrm{e}-14^{*}$ & $-20.87^{*}$ & -20.65 & -20.79 \\
\hline
\end{tabular}

Note. * indicates lag order selected by the criterion; LR: sequential modified LR test statistic; FPE: Final prediction error; AIC: Akaike information criterion; SC: Schwarz information criterion; HQ: Hannan-Quinn information criterion. 


\subsubsection{VAR Equations}

For all three periods, VAR (1) model is estimated. The estimtion output for P1, P2 and P3 are given below

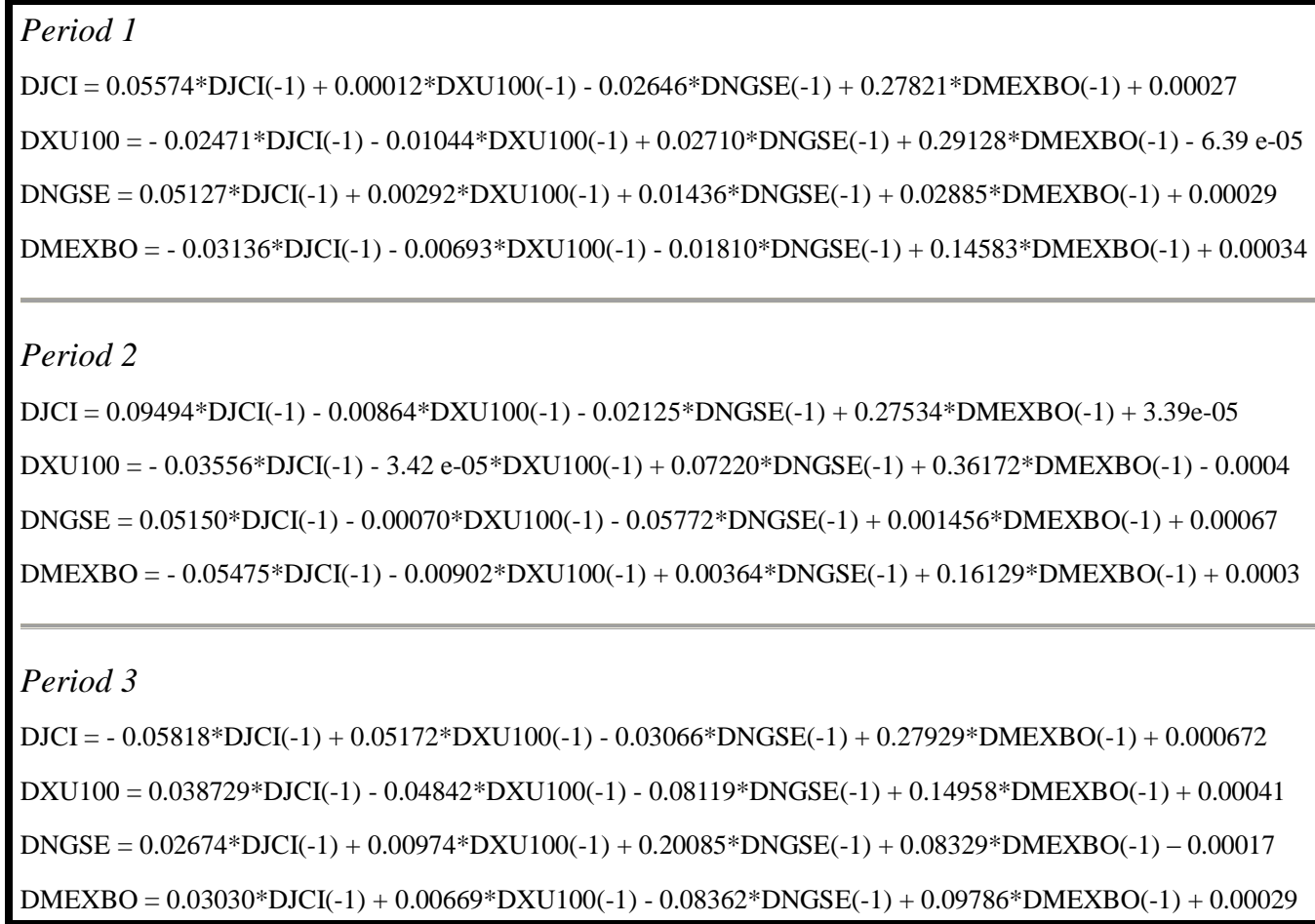

\subsubsection{Usefulness of VAR}

As explained above, VAR summary statistics are reported for the interpretation of the results. However, before interpreting the summary statistics, the usefulness of the VAR (1) models needs to be checked by conducting the VAR stability condition check and examining the residuals for autocorrelation.

The AR roots graphs, illustrated in Figure 2, confirm that no root lies outside the unit circle, thereby satisfying the stability condition of VAR model for the all periods.

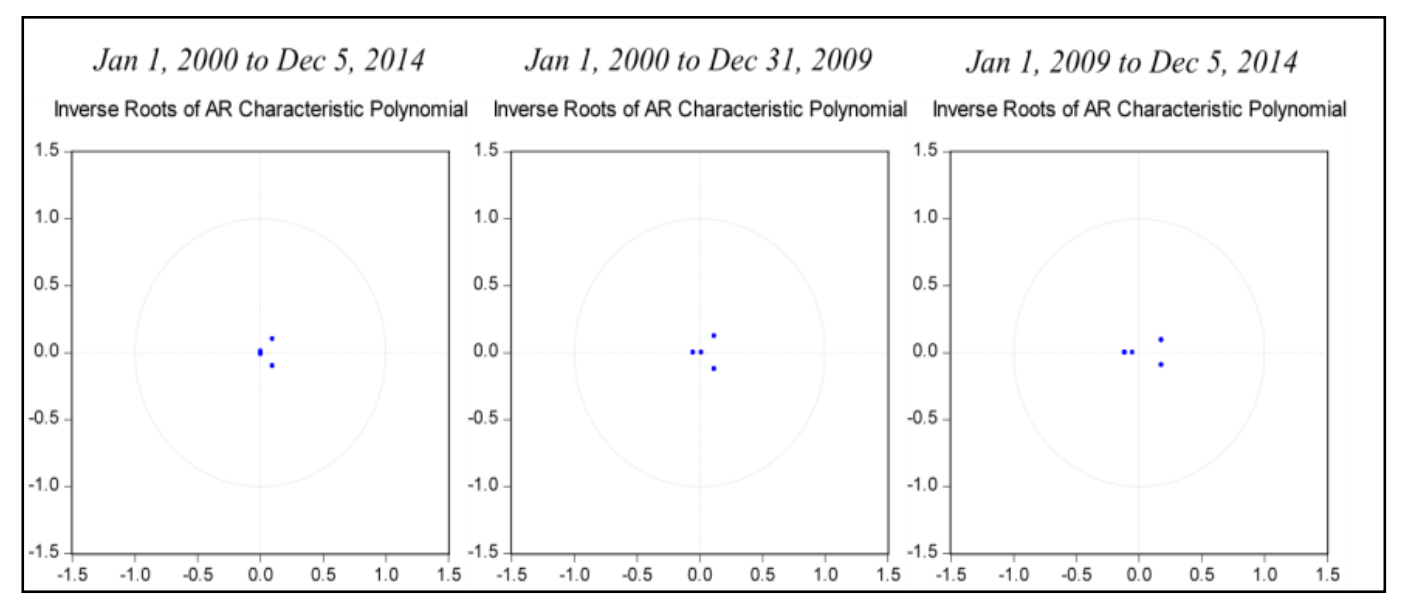

Figure 2. AR root graphs

To detect the presence of autocorrelation in the residuals, both VAR Residual Portmanteau Tests for Autocorrelations and VAR Residual Serial Correlation LM Tests were conducted. The computed Q-Stat and LM statistic were found to be statistically insignificant. Thus the VAR models estimated in the current study are 
found to be useful, as confirmed by the relevant test statistic.

\subsubsection{Summary Statistics}

In this study, Block Exogeneity Wald Test and variance decomposition estimations are reported for the interpretation of the VAR output for each period.

Unidirectional causality from MEXBO to JCI is confirmed by returns data for all three periods, as tabulated in Table 6. It has been inferred from low p-value of the test statistic. Causality from XU100 to JCI is confirmed by post-crisis period data. Further, XU100, NGSE and MEXBO also jointly cause JCI, as inferred from the p-value of 0.00 for all three periods.

Causality from MEXBO to XU100 is confirmed by returns data for all periods. Though XU100 is not caused by JCI and NGSE individually, yet these two markets along with MEXBO jointly cause XU100 as confirmed by analysis of data for all periods. Data for P1 and P2 confirm casuality from JCI to NGSE whereas casuality from MEXBO to NGSE is confirmed by data for P3. Further, XU100, JCI and MEXBO jointly cause NGSE, as confirmed by the analysis of returns data for all three periods.

Data for P1 and P2 confirm casuality from JCI to MEXBO whereas casuality from NGSE to MEXBO is confirmed by data for P3. Further, XU100, JCI and NGSE jointly cause MEXBO, as confirmed by the analysis of returns data for $\mathrm{P} 2$ and $\mathrm{P} 3$.

There is bidirectional causality between the Indonesian and Mexican markets, as confirmed by data for P1 as well as P2 and between the Nigerian and Mexican markets as confirmed by data for P3.

On the whole, the data from all three periods confirm that a set of any three markets jointly cause the excluded market. Further, the Mexican equity market seems to be becoming the influential market in the context of the MINT grouping in the recent past.

Table 6. Block exogeneity wald tests

\begin{tabular}{|c|c|c|c|c|c|c|c|c|c|}
\hline \multicolumn{4}{|c|}{ P1 } & \multicolumn{3}{|c|}{$\mathbf{P 2}$} & \multicolumn{3}{|c|}{ P3 } \\
\hline \multicolumn{4}{|c|}{ Dependent variable: DJCI } & \multicolumn{3}{|c|}{ Dependent variable: DJCI } & \multicolumn{3}{|c|}{ Dependent variable: DJCI } \\
\hline Excluded & Chi-sq & df & Prob. & Chi-sq & df & Prob. & Chi-sq & df & Prob. \\
\hline DXU100 & 0.0001 & 1 & 0.9904 & 0.4812 & 1 & 0.4879 & 5.083359 & 1 & 0.0242 \\
\hline DNGSE & 2.0382 & 1 & 0.1534 & 0.8138 & 1 & 0.3670 & 1.010207 & 1 & 0.3149 \\
\hline DMEXBO & 237.970 & 1 & 0.0000 & 139.9826 & 1 & 0.0000 & 87.49131 & 1 & 0.0000 \\
\hline All & 269.948 & 3 & 0.0000 & 149.056 & 3 & 0.0000 & 148.0475 & 3 & 0.0000 \\
\hline \multicolumn{4}{|l|}{ DXU100 } & \multicolumn{3}{|l|}{ DXU100 } & \multicolumn{3}{|l|}{ DXU100 } \\
\hline Excluded & Chi-sq & df & Prob. & Chi-sq & df & Prob. & Chi-sq & df & Prob. \\
\hline DJCI & 0.8468 & 1 & 0.3574 & 0.9658 & 1 & 0.3257 & 1.077533 & 1 & 0.2993 \\
\hline DNGSE & 0.7824 & 1 & 0.3764 & 3.0647 & 1 & 0.0800 & 3.705021 & 1 & 0.0542 \\
\hline DMEXBO & 95.4870 & 1 & 0.0000 & 78.7827 & 1 & 0.0000 & 13.12573 & 1 & 0.0003 \\
\hline All & 96.8316 & 3 & 0.0000 & 81.6939 & 3 & 0.0000 & 19.82375 & 3 & 0.0002 \\
\hline \multicolumn{4}{|l|}{ DNGSE } & \multicolumn{3}{|l|}{ DNGSE } & \multicolumn{3}{|l|}{ DNGSE } \\
\hline Excluded & Chi-sq & df & Prob. & Chi-sq & $\mathrm{df}$ & Prob. & Chi-sq & $\mathrm{df}$ & Prob. \\
\hline DJCI & 13.0754 & 1 & 0.0003 & 7.913122 & 1 & 0.0049 & 1.450557 & 1 & 0.2284 \\
\hline DXU100 & 0.10076 & 1 & 0.7509 & 0.004031 & 1 & 0.9494 & 0.266566 & 1 & 0.6056 \\
\hline DMEXBO & 3.35934 & 1 & 0.0668 & 0.005006 & 1 & 0.9436 & 11.49505 & 1 & 0.0007 \\
\hline All & 23.2506 & 3 & 0.0000 & 8.406320 & 3 & 0.0383 & 26.52405 & 3 & 0.0000 \\
\hline \multicolumn{4}{|l|}{ DMEXBO } & \multicolumn{3}{|l|}{ DMEXBO } & \multicolumn{3}{|l|}{ DMEXBO } \\
\hline Excluded & Chi-sq & df & Prob. & Chi-sq & df & Prob. & Chi-sq & df & Prob. \\
\hline DJCI & 3.92048 & 1 & 0.0477 & 7.847744 & 1 & 0.0051 & 1.161700 & 1 & 0.2811 \\
\hline DXU100 & 0.45182 & 1 & 0.5015 & 0.586947 & 1 & 0.4436 & 0.078472 & 1 & 0.7794 \\
\hline DNGSE & 1.00336 & 1 & 0.3165 & 0.026816 & 1 & 0.8699 & 6.921822 & 1 & 0.0085 \\
\hline All & 5.83886 & 3 & 0.1197 & 9.287364 & 3 & 0.0257 & 8.029646 & 3 & 0.0454 \\
\hline
\end{tabular}

Note. The highlighted boxes indicate statistically significant outcomes at $5 \%$ significance level.

Variance decomposition has been estimated for ten days and estimates of the days 1, 2, 3, 5 and 10 have been reported. Consistent with the model definition, contemporaneous variance of JCI can be attributed fully to its 
own shock. No contemporaneous variance of fluctuation in JCI on account of shocks in other three markets is observed or indeed expected because the VAR ordering rules out instantaneous change in a preceding variable in response to the changes in subsequent variables. On day 2, shock to JCI accounts for $93 \%$ of the variation of the fluctuation in itself. As tabulated in Table 7, innovation in other markets account for only $7 \%$ of variance of the fluctuation in JCI from day 2 through 10.

The same variance decomposition is observed for JCI using pre-crisis data separately. However, the post-crisis data shows some changes in variance decoposition for JCI. The shocks in JCI account for approximately $91 \%$ of variation in its fluctuation from day 2 through 10 and the effect of the other markets is $9 \%$. The impact of shocks in XU100 on variance of fluctuation in JCI is nearly $4 \%$ as per the $\mathrm{P} 3$ returns data.

In case of XU100, contemporaneous impact of its own shock is nearly $96 \%$ as per P1 data with $4 \%$ coming from innovation in JCI. From day 2 through 10, 93.5\% variation in XU100 comes from its own shock and the rest 6.5\% from the other markets. As per the P2 data, the instantaneous impact of its own shock on the variance of change in XU100 is nearly $98 \%$, which reduces to $94 \%$ subsequently. As per the P3 data, the variation of the fluctuation in XU100 in response to shock in itself is $86 \%$ on day 1 and $85 \%$ from day 2 onward. The effect of innovation in JCI on XU100 is observed to be $14 \%$ from day lin the post-crisis period.

Table 7. Variance decomposition

\begin{tabular}{|c|c|c|c|c|c|c|c|c|c|c|c|c|}
\hline \multicolumn{5}{|c|}{$\begin{array}{c}\text { Variance Decomposition for P1 } \\
\text { JCI }\end{array}$} & \multicolumn{4}{|c|}{$\begin{array}{c}\text { Variance Decomposition for P2 } \\
\text { JCI } \\
\end{array}$} & \multicolumn{4}{|c|}{$\begin{array}{c}\text { Variance Decomposition for P3 } \\
\text { JCI }\end{array}$} \\
\hline Period & $\mathrm{J}$ & $\mathrm{X}$ & $\mathrm{N}$ & $\mathrm{M}$ & $\mathrm{J}$ & $\mathrm{X}$ & $\mathrm{N}$ & $\mathrm{M}$ & $\mathrm{J}$ & $X$ & $\mathrm{~N}$ & $\mathrm{M}$ \\
\hline 1 & 100.00 & 0.00 & 0.00 & 0.00 & 100.00 & 0.00 & 0.00 & 0.00 & 100.00 & 0.00 & 0.00 & 0.00 \\
\hline 2 & 93.49 & 0.69 & 0.04 & 5.75 & 94.07 & 0.29 & 0.03 & 5.60 & 91.16 & 3.50 & 0.07 & 5.25 \\
\hline 3 & 93.26 & 0.71 & 0.05 & 5.96 & 93.74 & 0.30 & 0.03 & 5.91 & 91.09 & 3.50 & 0.13 & 5.26 \\
\hline 5 & 93.26 & 0.71 & 0.05 & 5.97 & 93.74 & 0.30 & 0.03 & 5.92 & 91.09 & 3.50 & 0.14 & 5.26 \\
\hline 10 & 93.26 & 0.71 & 0.05 & 5.97 & 93.74 & 0.30 & 0.03 & 5.92 & 91.09 & 3.50 & 0.14 & 5.26 \\
\hline \multicolumn{5}{|c|}{ XU100 } & \multicolumn{4}{|c|}{ XU100 } & \multicolumn{4}{|c|}{ XU100 } \\
\hline & $\mathrm{J}$ & $\mathrm{X}$ & $\mathrm{N}$ & $\mathrm{M}$ & $\mathrm{J}$ & $\mathrm{X}$ & $\mathrm{N}$ & M & $\mathrm{J}$ & $\mathrm{X}$ & $\mathrm{N}$ & M \\
\hline 1 & 4.01 & 95.98 & 0.00 & 0.00 & 2.18 & 97.81 & 0.00 & 0.00 & 14.11 & 85.88 & 0.00 & 0.00 \\
\hline 2 & 3.94 & 93.59 & 0.01 & 2.43 & 2.11 & 94.47 & 0.12 & 3.29 & 14.13 & 84.76 & 0.24 & 0.85 \\
\hline 3 & 3.94 & 93.56 & 0.02 & 2.46 & 2.11 & 94.41 & 0.12 & 3.34 & 14.13 & 84.74 & 0.26 & 0.86 \\
\hline 5 & 3.94 & 93.56 & 0.02 & 2.46 & 2.11 & 94.41 & 0.12 & 3.34 & 14.13 & 84.74 & 0.26 & 0.86 \\
\hline 10 & 3.94 & 93.56 & 0.02 & 2.46 & 2.11 & 94.41 & 0.12 & 3.34 & 14.13 & 84.74 & 0.26 & 0.86 \\
\hline \multicolumn{5}{|c|}{ NGSE } & \multicolumn{4}{|c|}{ NGSE } & \multicolumn{4}{|c|}{ NGSE } \\
\hline & $\mathrm{J}$ & $\mathrm{X}$ & $\mathrm{N}$ & $\mathrm{M}$ & $\mathrm{J}$ & $\mathrm{X}$ & $\mathrm{N}$ & $\mathrm{M}$ & $\mathrm{J}$ & $\mathrm{X}$ & $\mathrm{N}$ & M \\
\hline 1 & 0.21 & 0.02 & 99.76 & 0.00 & 0.57 & 0.00 & 99.42 & 0.00 & 0.08 & 0.69 & 99.22 & 0.00 \\
\hline 2 & 0.64 & 0.04 & 99.21 & 0.08 & 0.95 & 0.00 & 99.04 & 0.00 & 0.67 & 1.25 & 97.35 & 0.71 \\
\hline 3 & 0.65 & 0.05 & 99.16 & 0.12 & 0.95 & 0.00 & 99.02 & 0.02 & 0.73 & 1.32 & 97.11 & 0.83 \\
\hline 5 & 0.65 & 0.051 & 99.16 & 0.12 & 0.95 & 0.00 & 99.02 & 0.02 & 0.73 & 1.32 & 97.09 & 0.83 \\
\hline 10 & 0.65 & 0.05 & 99.16 & 0.12 & 0.95 & 0.00 & 99.02 & 0.02 & 0.73 & 1.32 & 97.09 & 0.83 \\
\hline \multicolumn{5}{|c|}{ MEXBO } & \multicolumn{4}{|c|}{ MEXBO } & \multicolumn{4}{|c|}{ MEXBO } \\
\hline & $\mathrm{J}$ & $\mathrm{X}$ & $\mathrm{N}$ & $\mathrm{M}$ & $\mathrm{J}$ & $\mathrm{X}$ & $\mathrm{N}$ & M & $\mathrm{J}$ & $\mathrm{X}$ & $\mathrm{N}$ & $\mathrm{M}$ \\
\hline 1 & 4.86 & 10.33 & $2.10 \mathrm{E}-05$ & 84.79 & 3.05 & 7.47 & 0.00 & 89.47 & 10.97 & 20.68 & 0.01 & 68.3 \\
\hline 2 & 4.77 & 10.25 & 0.02 & 84.93 & 3.07 & 7.36 & 0.00 & 89.55 & 11.17 & 20.55 & 0.45 & 67.8 \\
\hline 3 & 4.77 & 10.25 & 0.02 & 84.93 & 3.09 & 7.36 & 0.00 & 89.54 & 11.17 & 20.54 & 0.49 & 67.7 \\
\hline 5 & 4.77 & 10.25 & 0.02 & 84.93 & 3.09 & 7.36 & 0.00 & 89.54 & 11.17 & 20.54 & 0.50 & 67.7 \\
\hline 10 & 4.77 & 10.25 & 0.02 & 84.93 & 3.09 & 7.36 & 0.00 & 89.54 & 11.17 & 20.54 & 0.50 & 67.7 \\
\hline
\end{tabular}

Note. J stands for JCI, X for XU100, N for NGSE and M for Mexbo. Cholesky Ordering: DJCI DXU100 DNGSE DMEXBO.

More than $99 \%$ of the variation of the changes in NGSE on day 1 occurs on account of its own shock, as confirmed by the analysis of data for all three periods.Analysis of P1 data shows nearly $85 \%$ of the variance of the fluctuation in MEXBO comes from its own innovation from day 1 through 10. Of the remaining $15 \%, 10 \%$ comes from XU100 and 5\% from JCI for all days. Analyzing P2 data, the relevant percentages are observed to be $89 \%$ for MEXBO, more than $7 \%$ for XU100 and 3\% for JCI for all days.

As per P3 data, only $68 \%$ of the variance of the fluctuation in MEXBO comes from its own shock from day 1 to 
10. Of the remaining $32 \%$, significant impact of XU100 of more than $20 \%$ and that of JCI of more than $11 \%$ is seen for all days.

On the whole, it can be summarized that all four markets are becoming less isolated from eachother, as confirmed by changing variance decomposition in the post-crisis period. It can be said, though not conclusively, that the portfolio diversification advantages using these markets may prevail for short run only as they are showing increasing interdepence.

\section{Summary and Concluding Remarks}

This paper examines the dynamic linkages among equity markets of MINT countries using daily closing price data of their leading indices for the period from January 1, 2000 through December 5, 2014. The time series of all four indices is tested for stationarity by applying three unit root tests. Thereafter, to detect interdependencies among these markets, unidirectional and bidirectional causality is ascertained using Granger Causality test. Further, VAR framework is applied to study the response of each market to shocks in the changes in other markets.

Specifically, the following questions are addressed in this paper: (1) Is the correlation between the pairs of MINT markets low enough to offer advantages of portfolio diversification in short-run? (2) Can one MINT market help better predict any other MINT equity market? (3) Do other MINT markets account for variance in fluctuation of any one MINT market? (4) Has the nature of dynamic linkages among the MINT markets changed in the post global financial crisis 2008 period?

As for the first question, the correlation is found to be positive between few pairs of markets but it is low enough for these markets to offer some short-run advantages of diversification. Further, correlations between pairs of MINT markets have continued to be largely the same over the three periods under study.

With respect to the second question, existence of bidirectional or unidirectional causality between many pairs of markets indicates that they can potentially be used to better forecast other indices. Coming to the third question, the result of variance decomposition reveal that no market under study is completely isolated from the others, as shown by the fact that no variance of change is completely accounted for by a market's own innovation. However, for a 10-day horizon, the percentage of variation of the fluctuations of each market under study is accounted for by its own innovation to the extent of 85\%-99\%, except in case of MEXBO for the post-crisis period. This confirms that the fluctuations in each market under study are impacted to a only limited extent by all other markets under consideration.

Finally, the results of the study have confirmed that the dynamics of linkages among the four markets seem to be altering in the post-crisis era.

On the basis of various empirical tests, it is concluded that none of the MINT markets can be called an influential market in the context of transmission of shock. All markets show noticeable contemporaneous correlation with themselves and the effect of shock seems to fade out within two to three days.

However, these findings need to be contextualized in the view of certain limitations of the study. It should be clarified here that change in ordering of variables in VAR system could substantially impact the results of the tests. The author has based VAR order for the current study only on time zones as it is considered to be the most suitable way for sequencing time series related to financial markets. Testing the interdependencies using different VAR orders can make the study more robust and findings more conclusive.

Future research can be undertaken to ascertain the interdependencies among these markets by using different orders of varaibles for Cholesky decomposition. Further, this study can be taken forward by exploring the evolving economic relationship among MINT countries to better understand the changing dynamics observed in the post-crisis period.

\section{References}

Agiakloglou, C., \& Gkouvakis, M. (2015). Causal interrelations among market fundamentals: Evidence from the European Telecommunications sector. Quarterly Review of Economics \& Finance, 55, 150-159. http://dx.doi.org/10.1016/j.qref.2014.07.001

Akaike, H. (1974). A New Look at the Statistical Model Identification. I.E.E.E. Transactions on Automatic Control, AC 19, 716-723. http://dx.doi.org/10.1109/TAC.1974.1100705

Branson, W. H., \& Henderson, D. W. (1985). The specification and influence of asset markets. In R. W. Jones, \& P. B. Kenen (Eds.), Handbook of International Economics (Vol. 2., pp. 749-805). http://dx.doi.org/10.1016/S1573-4404(85)02006-8 
Cheng, H., \& Glascock, J. L. (2006). Stock market linkages before and after the asian financial crisis: Evidence from three greater China economic area stock markets and the US. Review of Pacific Basin Financial Markets and Policies, 9, 297-315. http://dx.doi.org/10.1142/S0219091506000732

Culbertson, K. (1996). Quantitative financial economics: Stocks, bonds and foreign exchange. Chichester, NH: John Wiley and Sons.

Dickey, D. A., \& Fuller, W. A. (1979). Distribution of the estimators for autoregressive time series with a unit root. Journal of the American Statistical Association, 74, 427-431. http://dx.doi.org/10.2307/2286348

Dickey, D. A., \& Fuller, W. A. (1981). Likelihood Ratio Statistics for Autoregressive Time Series with a Unit Root. Econometrica, 49. http://dx.doi.org/10.2307/1912517

Dungey, M., Fry, R., \& Martin, V. L. (2003). Equity Transmission Mechanisms from Asia to Australia: Interdependence or Contagion? Australian Journal of Management, 28, 157-182. http://dx.doi.org/10.1177/031289620302800203

Engle, R. (2002). Dynamic conditional correlation: A simple class of multivariate generalized autoregressive conditional heteroskedasticity models. Journal of Business and Economic Statistics, 20, 339-350. http://dx.doi.org/10.1198/073500102288618487

Erb, C. B., Harvey, C. R., \& Viskanta, T. E. (1994). Forecasting international equity correlations. Financial Analyst Journal, 50, 32-45. http://dx.doi.org/10.2469/faj.v50.n6.32

Francis, B., Hasan, I., \& Hunter, D. (2006). Dynamic relations between international equity and currency markets: The role of currency order flow. Journal of Business, 79, 219-257. http://dx.doi.org/10.1086/497417

Granger, C. W. J. (1969). Investigating Causal Relations by Econometric Models and Cross-Spectral Methods. Econometrica, 37, 424-438. http://dx.doi.org/10.2307/1912791

Granger, C. W. J. (1988). Some Recent Developments in a Concept of Causality. Journal of Econometrics, 39, 36-67. http://dx.doi.org/10.1016/0304-4076(88)90045-0

Grubel, H. G., \& Fadner, K. (1971). The Interdependence of International Equity Markets. Journal of Finance, 26, 89-94. http://dx.doi.org/10.1111/j.1540-6261.1971.tb00591.x

Hannan, E. J., \& Quinn, B. G. (1979). The determination of the order of an autoregression. Journal of the Royal Statistical Society, 41, 190-195.

Hildebrand, D. K. (1986). Statistical thinking for behavioral scientists. Boston, MA: Duxbury.

Hopkins, K. D., \& Weeks, D. L. (1990). Tests for normality and measures of skewness and kurtosis: Their place in research reporting. Educational and Psychological Measurement, 50, 717-729. http://dx.doi.org/10.1177/0013164490504001

Kayani, G. M., Hui, X., \& Gulzar, S. (2013). Financial Contagion: Mean Spillover Effect of US Financial Market to the Emerging Financial Markets in Perspective of Global Financial Crises. Journal of Convergence Information Technology, 8(17), 58-68. Accession Number: 100205699

Kwiatkowski, D., Phillips, P. C. B., Schmidt, P., \& Shin, Y. (1992). Testing the null hypothesis of stationarity against the alternative of a unit root. Journal of Econometrics, 54, 159-178. http://dx.doi.org/10.1016/0304-4076(92)90104-Y

Lessard, D. R. (1973). International Portfolio Diversification: A multivariate analysis for a group of Latin $\begin{array}{lllll}\text { American } & \text { countries. Journal of }\end{array}$ http://dx.doi.org/10.1111/j.1540-6261.1973.tb01384.x

Levy, H., \& Sarnat, M. (1970). International Diversification of Investment Portfolios. American Economic Review, 60, 668-675.

Lintner, J. (1965). Security Prices, Risk and Maximal Gains from Diversification. Journal of Finance, 20, 587-615. http://dx.doi.org/10.2307/2977249

Lutkepohl, H. (1993). Introduction to Multiple Time Series Analysis. New York, NY: Springer. http://dx.doi.org/10.1007/978-3-642-61695-2

MacKinnon, J. G. (1991). Critical Values for Cointegration Tests. In R. F. Engle, \& C. W. J. Granger (Eds.), Long-Run Economic Relationships: Readings in Cointegration. Oxford, MS: Oxford University Press. 
Markowitz, H. (1952). Portfolio Selection. Journal of Finance, 7, 77-91. http://dx.doi.org/10.1111/j.1540-6261.1952.tb01525.x

Meric, I., Kim, J. H., Linguo, G., \& Meric, G. (2012). Co-movements of and Linkages between Asian Stock Markets. Business \& Economics Research Journal, 3(1), 1-15. Accession Number :71101284

Mills, T. C. (1999). The Econometric Modeling of Financial Time Series (5th ed.). Princeton, NJ: Cambridge University Press. http://dx.doi.org/10.1017/CBO9780511754128

Morales, L. (2008). Volatility spillovers between equity and currency markets: Evidence from major Latin American countries. Cuadernos de Economia, 45,185-215.

Phillips, P. C. B., \& Perron, P. (1988). Testing for a Unit Root in Time Series Regression, Biometrika, 55, 277-301. http://dx.doi.org/10.1093/biomet/75.2.335

Quraishi, A. H., \& Nanjegowda, H. (2014). Impact of FII on S \& P NIFTY Index. International Journal of Research In Commerce, IT \& Management, 4(11), 5-9. Accession Number:101770260

Schwarz, G. (1978). Estimating the Dimension of a Model. The Annals of Statistics, 6, $461-464$. http://dx.doi.org/10.1214/aos/1176344136

Sharpe, W. (1964). Capital Asset Prices: A Theory of Market Equilibrium Under Conditions of Risk. Journal of Finance, 19, 429-442. http://dx.doi.org/10.2307/2977928

Solnik, B. H. (1974). Why not diversify internationally? Financial Analyst Journal, 30, 48-54. http://dx.doi.org/10.2469/faj.v30.n4.48

Tai, C. (2007). Market integration and contagion: Evidence from Asian emerging stock and foreign exchange markets. Emerging Markets Review, 8, 264-283. http://dx.doi.org/10.1016/j.ememar.2006.09.011

Tsay, R. (2001). Analysis of Financial Time Series. New York, NY: John Wiley \& Sons.

Wong, W. K., Penm, J., Terrell, R. D., \& Lim, K. Y. C. (2004). The Relationship between Stock Markets of Major Developed Countries and Asian Emerging Markets. Journal of Applied Mathematics and Decision Sciences, 8, 201-218. http://dx.doi.org/10.1155/S1173912604000136

Yang, S., \& Doong, S. (2004). Price and volatility spillovers between stock prices and exchange rates: Empirical evidence from the G-7 countries. International Journal of Business and Economics, 3, 139-153.

Yang, Y., \& Chang, C. (2008). A double-threshold GARCH model of stock market and currency shocks on stock returns. Mathematics and Computers in Simulation, 79, 458-474. http://dx.doi.org/10.1016/j.matcom.2008.01.048

\section{Copyrights}

Copyright for this article is retained by the author(s), with first publication rights granted to the journal.

This is an open-access article distributed under the terms and conditions of the Creative Commons Attribution license (http://creativecommons.org/licenses/by/3.0/). 